\title{
Serotonin platelet-transporter measures in childhood attention-deficit/hyperactivity disorder (ADHD): clinical versus experimental measures of impulsivity
}

\author{
Robert D. Oades, Michael Slusarek, Silke Velling, Brigitta Bondy ${ }^{1}$ \\ 2002 World Journal of Biological Psychiatry, 3, 96-100 \\ University Clinic for Child and Adolescent Psychiatry, Essen and Psychiatric Hospital, Munich ${ }^{1}$, \\ Germany.
}

\begin{abstract}
:
Impulsivity in terms of aggression, suicide or poor cognitive control has been associated with low synaptic availability of serotonin (5-HT) in adults and children. However characteristics of the 5-HT transporter have not been studied in children with attention-deficit/hyperactivity disorder (ADHD: combined type) where impulsivity is a core symptom. Here, in 20 children with ADHD, we explore the relationship of the density (Bmax) and affinity $(\mathrm{Kd})$ of the platelet $5-\mathrm{HT}$ transporter measured with $\left[{ }^{3} \mathrm{H}\right]$ paroxetine to both clinical ratings of impulsivity (Conners' Parent Questionnaire), and an experimental measure of impulsivity (the ability to withhold a prepotent response in the "stop-signal" paradigm). Decreases of affinity (increased $\mathrm{Kd}$ ) correlated with a low probability of response inhibition, but not with the clinical ratings of impulsivity. However, ratings of distractibility and impulsivity correlated with the experimental measure of response-inhibition. In contrast, increased transporter affinity (low Kd) correlated modestly with higher ratings of aggressive and externalising behaviour. Bmax was not associated with any behavioural score. We conclude that the synaptic availability of $5-\mathrm{HT}$ is under the control of the 5-HT transporter binding site affinity and that low affinity may be related to cognitive impulsivity (distractibility). Increased affinity of the transporter may also be related to conduct disturbance.
\end{abstract}

Key Words:

Childhood ADHD, distractibility, externalising behaviour, impulsivity, serotonin, transporter.

\section{Correspondence:}

Robert D. Oades PhD, Clinic for Child and Adolescent Psychiatry, University of Duisburg- Essen, Virchowstr. 174, 45147 Essen, Germany

\section{Acknowledgements:}

We are very grateful to Ms Alexandra Schieler for her help with the biochemical assay.

\section{Introduction:}

Severe attention-deficit/hyperactivity disorder (ADHD) in children is usually treated with psychostimulant drugs, such as methylphenidate. Some improvement may be seen in up to $80 \%$ of patients (Swanson et al 1998). Clinical response is interpreted in terms of enhancing a hypoefficient dopamine system (Malone et al 1994), particularly in children with the hyperactive/impulsive subtype (DSMIV). An alternative noradrenergic theory (Heilman et al 1991) may account for depressed activity in systems using noradrenaline as transmitter (Oades 1987) and be especially pertinent to the inattentive subtype (Lockwood et al 2001). But, interpretations here may be complicated by changes in other colocalized modulators like neuropeptide $Y$ (Oades et al 1999). Past reviews considered 
catecholaminergic alterations as primary, to the exclusion of serotonergic systems (Oades 1987, Zametkin and Rapaport 1987). This is surprising in view of the widely acknowledged attribution of changed serotonin (5-HT) transmission to some forms of impulsivity (Soubrie 1986), and the high heritability for ADHD-combined subtype for which impulsivity is a core feature (Rutter et al 1999). Further, in an animal model of ADHD (dopamine transporter knockout), hyperactive responsivity is modulated by the synaptic availability of serotonin (Gainetdinov et al 2000).

In a non-ADHD context (e.g. borderline personality disorder, suicide) impulsivity in terms of abrupt bursts of behaviour and aggression has been associated with reduced 5-HT activity (e.g. lower CSF levels of 5-HIAA: Kavoussi et al 1997). In aggressive children with ADHD there are also indications from provoked prolactin release for reduced 5-HT activity (Halperin et al 1997). Further, as in attempted suicide in adults (Engstrom et al 1999), in ADHD patients reduced HVA/5-HIAA ratios may be related to poor cognitive and inhibitory control (Oades 2002). Thus, one might predict that features leading to the reduced synaptic availability of $5-\mathrm{HT}$ would relate to impulsive reactivity: but it will be noted that that low HVA/5-HIAA ratios would result from increased 5-HT metabolism. As the 5-HT transporter prominently controls the availability of $5-\mathrm{HT}$ in the synapse, an exploration of the binding characteristics of platelet 5-HT transporters, a model for the central transporter receptor (Cheetham et al 1993) and their relationship to impulsivity in children with ADHD was conducted.

Children were recruited from those presenting to a newly advertised screening programme, from which the subgroup tested were those recommended to receive medication, for which a blood sample was necessary. The screening programme allowed clinical ratings of impulsivity as well as an experimental measure of the (in)ability to withhold a prepotent response at short notice (stop-paradigm: Slusarek et al. 2001) to be compared with 5-HT transporter measures.

\section{Methods:}

Twenty children with a pervasive hyperkinetic disturbance (ICD-10: WHO), equivalent to the combined type (DSM-IV 314.01) were recruited. Biochemical data were obtained from 13 boys and 3 girls (mean age 10.4y, sd 2.4 , range 7.2-14.5y) with a performance IQ of 87.4 (sd 14.0). Two had a simple hyperkinetic disorder (F90.0) and 14 hyperkinetic disorder of social behaviour (F90.1 that includes elements of DSM-IV 313.81); of these four had a secondary emotional disturbance (two with F93.8, one 94.1 and one 43.25). After receiving approval for the study from the faculty Ethics Committee, the children provided oral and the parents written informed consent to participation. The parents completed the Child Behaviour Checklist (CBCL: Achenbach and Edelbrock, 1983) and the Conners' Parent rating scale (Goyette et al. 1978). The sum score for Conners' ratings was 20.8 (sd 1.27). Exclusion criteria included the diagnosis of learning disorders, a score of $<17$ on the Conners' scale and a T score $\angle 60$ on the $\mathrm{CBCL}$ attention scale. The present analysis was restricted to the $\mathrm{CBCL}$ scales for internalising (mean 68.9 sd 1.8), externalising (mean 71.8 sd 1.6) and aggressive behaviour (mean 75.9 sd 2.1), and to 4 of the ten items on the Conners' scale relevant to impulsivity (i.e. C1 activity [mean $2.3 \mathrm{sd} 0.21$ ], C2 impulsivity [mean $2.3 \mathrm{sd} 0.18$ ], C5 fidgeting [mean $2.1 \mathrm{sd}$ 0.20 ], C6 distractibility [mean $2.4 \mathrm{sd} 0.16$ ]).

The stop-signal task was a forced-choice reaction time (RT) task. In the primary task children were asked to respond quickly and accurately with a left or right computer key when they saw an " $X$ " appear to the left or right of a fixation point on the computer screen. After 20 trials to allow familiarisation with the task and 10 further trials for calculation of the individual mean RT, the secondary task was introduced. Here a 'StopSignal' was presented with an auditory $1 \mathrm{kHz}$, $500 \mathrm{~ms}$ tone on $25 \%$ of 192 trials after the target. The Stop-Signal was presented 50, 200, 350 or $500 \mathrm{~ms}$ before the expected response. The inter-stimulus interval was $7 \mathrm{sec}$. The stopsignal reaction time (SSRT) is the time between presentation of the stop-signal and the inhibition of response, estimated from the RT 
distribution in the primary task (Logan 1994). Logan's probability of inhibition (p-inhibit) was also calculated for each of the different stopsignal delays. Data for the 50 and $500 \mathrm{~ms}$ intervals did not distinguish ADHD from healthy children due to floor and ceiling effects, respectively. Thus analysis here is restricted to the 200 and 350 ms intervals.

Platelets were prepared from platelet-rich plasma ( $25 \mathrm{ml}$ EDTA blood) and stored as pellets at $-80^{\circ} \mathrm{C}$ prior to analysis of $5-\mathrm{HT}$ transporter binding features after the method of Maguire et al (1993). After thawing and homogenisation of the pellets in hypotonic lysis buffer, cells were washed in Tris- $\mathrm{HCl}$ (70 $\mathrm{mmol} / \mathrm{l}$ ) and solubilized in an assay buffer (Tris $\mathrm{HCl} 50 \mathrm{mmol} / \mathrm{l} ; \mathrm{NaCl} 120 \mathrm{mmol} / \mathrm{l} ; \mathrm{KCl} 5 \mathrm{mmol} / \mathrm{l}$; $\mathrm{pH}$ 7.5). Binding was performed using 6 different concentrations of ${ }^{3} \mathrm{H}$-paroxetine (0.2$5 \mathrm{nmol} / \mathrm{l})$. Unspecific binding was assessed by $1 \mu \mathrm{mol} / \mathrm{l}$ fluoxetine in parallel experiments. The assay was carried out in a final volume of $250 \mu \mathrm{l}$ incubating for 2 hours at $20^{\circ} \mathrm{C}$. The reaction was stopped through rapid filtration (GF/F filter Whatman) and radioactivity measured in a Beckman scintillation counter.

Spearman correlation coefficients were calculated for comparisons of clinical and experimental behavioural indices with biochemical measures. Linear regression analyses with up to a maximum of 3 variables to predict impulsivity and the biochemical measures were used to seek support for the exploratory correlations.

\section{Results:}

The mean platelet count for the children was $266 \times 10^{3} / \mu \mathrm{l}$ (sd 58.7, range 189-386). The mean values for Bmax and $\mathrm{Kd}$ were respectively $3682 \mathrm{fmol} / \mathrm{mg}$ protein (sd 2684.2) and $0.424 \mathrm{nmol} / \mathrm{l}$ (sd 0.356). The experimental indices on the stop-signal task ( $p$-inhibit) were
0.33 and 0.54 (SSRT 468 and $488 \mathrm{~ms}$ ) for the 200 and $350 \mathrm{~ms}$ intervals, respectively. Comparative values from healthy children for p-inhibit were 0.46 and 0.80 (SSRT 225 and $235 \mathrm{~ms}$ ) at 200 and $350 \mathrm{~ms}$, respectively. The clinical, experimental and biochemical measures were not associated with the age or the IQ of the children.

There were no significant correlations for the Bmax of the 5-HT transporter with either the clinical ratings or the experimental measures ( $p$-inhibit/SSRT). However, figure 1 shows that on the stop-signal task decreasing $\mathrm{p}$-inhibit correlated with increasing $\mathrm{Kd}$ values (i.e. decreasing affinity). Similar associations were found for the SSRT (figure 1). Kd was not associated with any of the Conners' clinical ratings. However, the experimental p-inhibit measures at $350 \mathrm{~ms}$ on the stop-signal task showed a modest relationship to the scales of impulsivity $(r=-0.51, p=0.05)$ and distractibility $(r=-0.46, p=0.08)$.

Linear regressions confirmed that the experimental measures ( $p$-inhibit at 200 and $350 \mathrm{~ms}$ ) tended to predict $\mathrm{Kd}$ for the 5-HT transporter ( $p$-inhibit-350, partial correlation 0.50, $p=0.06, R^{2} 48.9$ ) but Conners' and CBCL ratings made no significant contribution. Indeed the biochemical measures ( $\mathrm{Kd}$, Bmax, F $[2,12]=4.2, p=0.04)$ predicted $p$-inhibit-350 on the stop -signal task ( $\mathrm{Kd}$, partial correlation -0.63, $\left.p=0.014, R^{2} 3.7\right)$, and Conners' ratings (fidgeting, impulsivity, distractibility; $F[3,11]=$ $4.0 \mathrm{p}=0.038$ ) contributed similarly to an explanation of the p-inhibit-350 measure, (distractibility: partial correlation $-0.57, \mathrm{p}=$ $\left.0.038, R^{2} 37.4\right)$.

Further, we noted a modest correlation for increasing externalising and aggressive behaviour with lower $\mathrm{Kd}$ values for the $5-\mathrm{HT}$ transporter: increasing affinity correlated similarly with both ratings: $r=-0.4, p=0.04$ ). 
Probability of response inhibition (stop signal $200 \mathrm{~ms}$ before) vs. Kd affinity (of paroxetine binding)

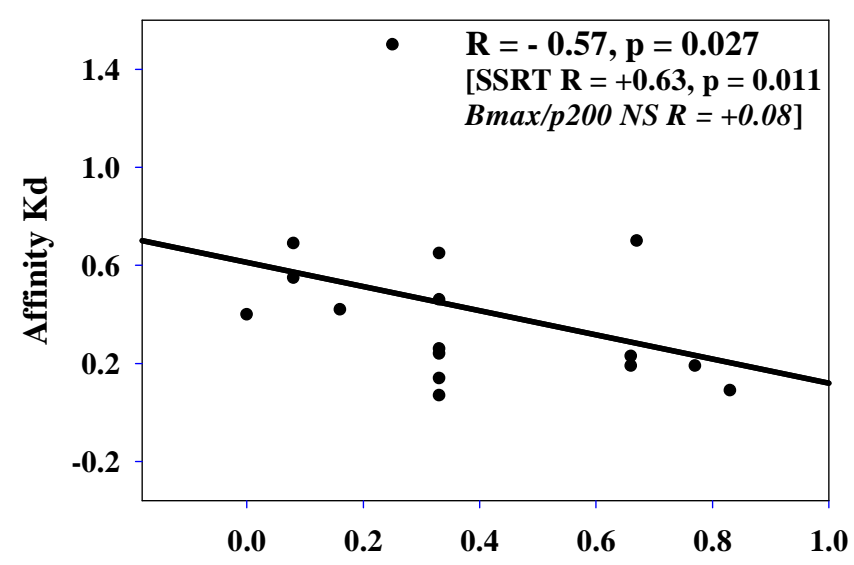

Probability (at $200 \mathrm{~ms}$ ) of inhibiting a response

Probability of response inhibition (stop-signal $350 \mathrm{~ms}$ before) vs. Kd affinity (of paroxetine binding)

\section{Figure 1:}

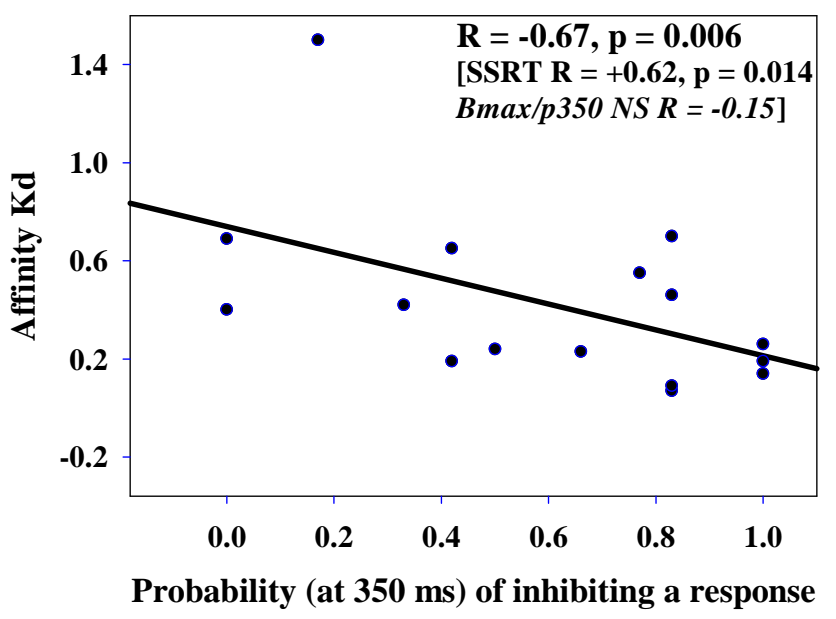

The affinity (Kd) of the 5-HT transporter binding site (nmol/l) is plotted against the probability of inhibiting a response in the "stop-signal" task, where stop signal intervals of $200 \mathrm{~ms}$ and $350 \mathrm{~ms}$ before the expected mean response time for 16 ADHD children are shown in the top and bottom diagram, respectively. (The single high $\mathrm{Kd}$ value is attributable to a $10 \mathrm{y}$ old girl with a mild comorbid disturbance of bonding.)

\section{Discussion}

This preliminary study of the potential contribution of the 5-HT transporter binding site to measures of impulsivity in children with ADHD throws up three points of interest. First, the relevant features of the transporter in the platelet model are not the number or density of binding sites (Bmax) but its affinity (Kd). Increasing difficulty with inhibiting response in the stop-signal task was correlated with decreasing receptor affinity. Second, while clinical ratings of impulsivity were not related to the transporter $(\mathrm{Kd})$, they and, to a greater extent, ratings of distractibility were associated with the experimental likelihood of withholding a response. Third there was a modest correlation between increasing affinity of the transporter receptor and increasing disruptive behaviour. This latter seems to support reports that indices of lower 5-HT activity coincide with the expression of violent behaviour (see introduction).

This preliminary investigation did not attempt to compare diagnosis-dependent differences for 5-HT transporter measures. However, the 
Bmax values were comparable with reports from impulsive and non-impulsive adult suicide attempters (Verkes et al 1998), normal 11-12 year-old male and female children (Sigurdh et al 1999) and adolescents with conduct disorder (Unis et al 1997). The Kd values were also comparable, except that the median value cited by Sigurdh et al was somewhat lower, probably reflecting minor methodological differences (pers. comm. Oct. 2001). We are unable to say if the higher values in the present study and that of Unis et al reflect the related disorders of ADHD (here) and conduct disorder (Unis et al)

How should differences of Kd be interpreted? Reductions of binding site affinity should normally be off-set by increased receptor capacity. It may be assumed that where this does not occur that more 5-HT remains available in the synapse. If this increase is associated with impulsivity then it stands in contrast to studies in adult subjects (see introduction).

For an alternative explanation the question then shifts to whether the association with a decreased likelihood of response inhibition reflects a relationship to impulsivity? It seems intuitive to describe a reduced ability to inhibit a response tendency as one that reflects an impulsive disposition, one that is not planned, poorly controlled, inaccurate or maladaptive (Solanto et al 2001). But, this description could apply to rapid responses to an irrelevant distracter that would normally be inhibited. Thus, it would also be possible to describe unusually fast reactions to the stop-signal as reflecting an impulsive disposition of the subjects. It is instructive that the clinical ratings that predicted $\mathrm{p}$-inhibit closest were those of 'distractibility', albeit that the relationship was negative. Thus, the least 'distractible' children were most likely to inhibit a response. Those who were less likely to inhibit responses (the more distractible) showed a lower 5-HT transporter affinity with putatively greater synaptic availability of $5-\mathrm{HT}$. This is consistent with a report of an association of poorer signal detection indices on sustained attention tasks with 5-HT metabolism (Oades 2000). Clearly a new and larger sample of children should be examined to test this proposal with a contrast of 5-HT measures in those rated high or low on distractibility and impulsivity ratings, backed up with continuous performance test measures of commission errors (impulsive cognition).

Thus an apparent conflict with the literature on 5-HT and impulsivity may be resolved in terms of the information processing involved in the experimental measures. The apparent increased affinity (lower synaptic 5-HT availability) in those with more externalising and aggressive behaviour is concordant with the literature. Children with a stable diagnosis of ADHD, especially those with the combined subtype are likely to show marked conduct disturbance (August et al 1998; Faraone et al 1998). But both hyperactive and nonhyperactive children with conduct disturbance are likely to show impulsive behaviour (Taylor 1998). Thus, our evidence of differential associations of types of impulsive cognition and impulsive aggression with features controlling the availability of 5-HT warn against premature use of adjunctive serotonergic medication without detailed consideration of the individual's symptoms. While it may seem likely that antagonists (of the uptake or the postsynaptic site) could be beneficial in some circumstances (disruptive behaviour), inappropriate use could exacerbate the patient's tendencies to poor stimulus-response control with potential longterm consequences for risk-taking behaviour and substance misuse. 


\section{References:}

Achenbach TM, Edelbrock CS (1983) Manual for the Child Behavior Checklist and revised Child Behavior Profile. Burlington: University of Vermont.

August GJ, Braswell L, Thuras P (1998) Diagnostic stability of ASDHD in a community sample of school-aged children screened for disruptive behavior. J Abnorm Child Psychology 26: 345-356.

Cheetham SC, Viggers JA, Slater NA, Heal DJ, Buckett WR (1993) $\left[{ }^{3} \mathrm{H}\right]$ Paroxetine binding in rat frontal cortex strongly correlates with [ $\left.{ }^{3} \mathrm{H}\right]$ $5 \mathrm{HT}$ uptake: effect of administration of various antidepressant treatments. Neuropharmacol 32: 737-743.

Engstrom G, Alling C, Blennow K, Regnell G, Traskmann-Bendz L (1999) Reduced cerebrospinal HVA concentrations and HVA/5HIAA ratios in suicide attempters monoamine metabolites in 120 suicide attempters and 47 controls. Eur Neuropsychopharmacol. 9: 399-405.

Faraone SV, Biederman J, Weber W, Russell RL (1998) Psychiatric, neuro-psychological and psychosocial features of DSM-IV subtypes of attention-deficit/ hyperactivity disorder: results from a clinically referred sample J Am Acad Child Adolesc Psychiatry 37: 185-193.

Gainetdinov RR, Wetsel WC, Jones SR, Levin ED, Jaber M, Caron MG (1999) Role of serotonin in the paradoxical effect of psychostimulants on hyperactivity Science 283: 397-401.

Goyette CH, Conners CK, Ulrich RF (1978) Normative Data on the Revised Conners Parent and Teacher Rating Scales. J Abnorm Child Psychology 6: 221-236.

Halperin JM, Newcorn JH, Kopstein I, McKay KE, Schwartz ST, Siever LJ, Sharma V (1997) Serotonin, aggression and parental psychopathology in children with attentiondeficit hyperactivity disorder. J Am Acad Child Adolesc Psychiatry 36: 1391-1398.
Heilman KM, Voeller KKS, Nadeau SE (1991) A possible pathophysiological substrate of attention deficit hyperactivity disorder. J Child Neurology 6: 76-81.

Kavoussi R, Armstead P, Coccaro EF (1997) The neurobiology of impulsive aggression. Psychiat Clin N Am 20: 395-403.

Lockwood KA, Marcotte AC, Stern C (2001) Differentiation of attention-deficit/ hyperactivity disorder subtypes: application of a neuropsychological model of attention. J Clin Exp Neuropsychology 23: 317-330.

Logan GD (1994) On the ability to inhibit thought and action: a user's guide to the stop signal paradigm. In : Dagenbach D, Carr T (eds) Inhibitory processes in attention, memory and language, Academic Press, San Diego, pp 189240.

Maguire K, Tuckwell V, Pereira A, Dean B, Singh B (1993) Significant correlation between ${ }^{14} \mathrm{C}-5-\mathrm{HT}$ uptake and ${ }^{3} \mathrm{H}$-paroxetine binding to platelets from healthy volunteers. Biol Psychiatry 34: 356-360.

Malone MA, Kershner JR, Swanson JM (1994) Hemispheric processing and methylphenidate effects in ADHD. J Child Neurology 9: 181-189.

Oades RD (1987) Attention deficit disorder with hyperactivity (ADDH): contribution of catecholaminergic activity. Prog Neurobiology 29: 365-391.

Oades RD (2000) Differential measures of 'sustained attention' in children with attention-deficit/hyperactivity or tic disorders: relations to monoamine metabolism. Psychiat Res 93: 165-178.

Oades RD (2002) Dopamine (DA) may be 'hyper' with respect to noradrenaline (NA) metabolism, but 'hypo' with respect to serotonin (5-HT) metabolism in ADHD children. Behav Brain Res in press.

Oades RD, Daniels R, Rascher W (1998) Plasma neuropeptide- $Y$ levels, monoamine metabolism, electrolyte excretion and drinking 
behavior in children with attention-deficit hyperactiv-ity disorder. Psychiatry Res 80: 177-186.

Rutter M, Silberg J, O'Connor T, Simonoff E, (1999) Genetics and child psychiatry: II empirical research findings. J Child Psychol Psychiatry 40: 19-55.

Sigurdh J, Spigset O, Allard P, Mjörndal T, Hägglöf $B$ (1999) Binding of $\left[{ }^{3} \mathrm{H}\right]$ lysergic acid diethylamide to serotonin $5-\mathrm{HT}_{2 \mathrm{~A}}$ receptors and of $\left[{ }^{3} \mathrm{H}\right]$ paroxetine to serotonin uptake sites in platelets from healthy children, adolescents and adults. Neuropsychobiol 40: 183-187.

Slusarek M, Velling S, Bunk D, Eggers C (2001) Motivational effects on inhibitory control in children with ADHD. J Am Acad Child Adolesc Psychiatry 40: 355-363.

Solanto MV, Abikoff $H$, Sonuga-Barke $E$, Schachar R, Logan GD, Wigal T, Hechtman L, Hinshaw S, Turkel E (2001) The ecological validity of delay aversion and response inhibition as measures of impulsivity in AD/HD: a supplement to the NIMH multimodal treatment study of $A D / H D$. J Abnorm Child Psychology 29: 215-228.

Soubrie P (1986) Reconciling the role of central serotonin neurons in human and animal behavior. Behav Brain Sci 9: 319-364.
Swanson JM, Sergeant JA, Taylor E, SonugaBarke EJS, Jensen PS, Cantwell DP (1998) Attention-deficit hyperactivity disorder and hyperkinetic disorder. Lancet 351: 429-432.

Taylor E (1998) Clinical foundations of hyperactivity research. Behav Brain Res 94: 11-24.

Unis AS, Cook EH, Vincent JG, Gjerde DK, Perry BD, Mason C, Mitchell J (1997) Platelet serotonin measures in adolescents with conduct disorder. Biol Psychiatry 42: 553-559.

Verkes RJ, Van der Mast RC, Kerkhof AJFM, Fekkes D, Hengeveld MW, Tuyl JP, Van Kempen GMJ (1998) Platelet serotonin, monoamne oxidase activity and $\left[{ }^{3} \mathrm{H}\right]$ paroxetine binding related to impulsive suicide attempts and borderline personality disorder. Biol Psychiatry 43: 740-746.

World Health Organization: Tenth revision of the International Classification of Diseases, Chapter V (F): Mental and Behavioural Disorders (including disorders of psychological development). Clinical Descriptions and Diagnostic Guidelines. Bern: Huber, 1991

Zametkin AJ, Rapoport JL (1987) Neurobiology of attention deficit disorder with hyperactivity: where have we come in 50 years? J Am Acad Child Adolesc Psychiatry 26: 676-686. 